\title{
Diverse demographic histories in a guild of hymenopteran parasitoids
}

\author{
William Walton ${ }^{1}$, Graham Stone ${ }^{1}$, and Konrad Lohse ${ }^{1}$ \\ ${ }^{1}$ University of Edinburgh
}

May 4, 2021

\begin{abstract}
Signatures of past changes in population size have been detected in genome-wide variation in many species. However, the causes of such demographic changes and the extent to which they are shared across co-distributed species remain poorly understood. During Pleistocene glacial maxima, many temperate European species were confined to southern refugia. While vicariance and range expansion processes associated with glacial cycles have been widely studied, little is known about the demographic history of refugial populations, and the extent and causes of demographic variation among co-distributed species. We used whole genome sequence data to reconstruct and compare demographic histories during the Quaternary for Iberian refuge populations in a single ecological guild (seven species of chalcid parasitoid wasps associated with oak cynipid galls). We find support for large changes in effective population size through the Pleistocene that coincide with major climate events. However, there is little evidence that the timing, direction and magnitude of demographic change are shared across species, suggesting that demographic histories are largely idiosyncratic even at the scale of a single glacial refugium.
\end{abstract}

\section{Hosted file}

Comparative_demography_reveals_congruent_population_size_trajectories_across_species_of_hymenopteran_pa available at https://authorea.com/users/411878/articles/520763-diverse-demographichistories-in-a-guild-of-hymenopteran-parasitoids 